boiling alcohol or boiling ethyl acetate, the extracts combined, concentrated, and the concentrated solution allowed to cool. Pale, reddish-brown needles of the aminoquinazoline separated, in poor yield.

Calculated for $\mathrm{C}_{9} \mathrm{H}_{9} \mathrm{ON}_{3}: \mathrm{N}$, 24.0. Found: $\mathrm{N}$, 24.0.

This aminoquinazoline melts with decomposition at $295-310^{\circ}$. It slowly darkens in the light. It is moderately soluble in alcohol, acetone or ethyl acetate, when boiling, less so when cold, and is practically insoluble in cold water, benzene or ether. In dilute caustic alkalies, it dissolves readily, and is reprecipitated from such solutions by carbon dioxide or by dilute acids. It is also soluble in strong hydrochloric acid.

Hydrochloride.-Dry hydrogen chloride, passed into an ethyl acetate solution of the aminoquinazoline, caused the separation of the hydrochloride as a nearly white crystalline precipitate. This salt is dissociated when boiled with plenty of water.

Chlorplatinate.-The hydrochloride was dissolved in a small amount of dilute hydrochloric acid, and treated with a solution of chlorplatinic acid. The chlorplatinate separated at once as a crystalline precipitate.

Calculated for $\left(\mathrm{C}_{9} \mathrm{H}_{9} \mathrm{ON}_{3} \cdot \mathrm{HCl}\right)_{2} \mathrm{PtCl}_{4}: \mathrm{Pt}$, 25.66. Found: $\mathrm{Pt}$, 25.56 .

HaVemeyer I,ABORATORIES, CoLUMBIA UNIVERSiTy, December, Ig05.

[CONTRIBUTION FROM THE TEXAS EXPERIMENT STATION.]

\title{
NITRIFICATION AND AMMONIFICATION OF SOME FERTILIZERS.
}

BY G. S. FRAPS.

Received October 3 I, 1905 .

IN IgoI, Withers and Fraps found ${ }^{1}$ that in a certain soil, the amount of nitrates produced from organic materials was in the order of their availability as measured by vegetation tests and solubility in potassium permanganate. A later study by the same authors ${ }^{2}$ showed that this relation does not hold for all soils, but the rank of the fertilizer, if measured by nitrates formed under similar conditions, varied with different soils. Placing

1 This Journal, 23, 318 (190r).

${ }^{2}$ Report for the N. C. Experiment Station for 1902-'O3, p. $3^{1}$. 
the nitrogen oxidized from cotton-seed meal as Ioo, the rank of the others varied in five soils as follows:

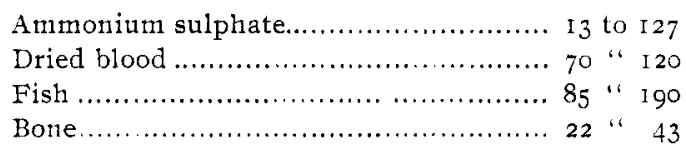

Plants, however, can assimilate not only nitrates, but also ammonium salts, and certain organic nitrogenous bodies, such as tyrosin, urea, etc. Consideration of this fact leads to the determination of the ammonia formed as well as nitrates.

The further study of the nitrification and ammonification of organic materials to be described in this paper, has not only given some explanation for the variations noted above, but also justifies the following statement: While the relative amounts of nitrates produced from different materials in different soils under comparable conditions depend largely upon the nature of the soil, the production of ammoniacal plus nitric nitrogen depends almost entirely upon the nature of the material.

\section{METHOD OF WORK.}

It is known that soils vary widely in "nitrifying power," that is, ability to serve as mediums for the growth and development of nitrifying organisms. For the purpose of this investigation, three soils were selected which differed considerably in nitrifying power:

Soil 75 was a poor white sand from Nacogdoches, Texas, low in nitrifying power, and of low water capacity.

Soil 77 was a brown clay loam from College Station, Texas, of medium nitrifying power, good water capacity and responding well to applications of phosphoric acid.

Soil 13 I was a brown soil termed Orangeberg, a fine sandy loam, from Elmendorf, Texas.

The nitrification tests were conducted as follows: Five hundred grams of dry soil were mixed with 20 grams nitrifying earth, soil from a field, which was moist and contained the nitrifying organism, an amount of nitrogenous substance containing 0.3 gram of nitrogen, and water equal to one-third of the saturation capacity of the soil. The nitrogenous substance and nitrifying earth were first mixed, then these were incorporated with the dry soil, the water added, and the whole mixed thoroughly until the mass was

${ }^{1}$ Am. Ch. J. 29, 225 (I903). 
uniform. The mixture was placed in $500 \mathrm{cc}$. precipitating jars, shaking it down by tapping gently against a wooden block, or by the hand. A test-tube with a small perforation in the end was inserted to the depth of about an inch, the jar and its contents weighed, and placed in a water-bath kept as nearly as possible at $35^{\circ} \mathrm{C}$. The most satisfactory method of marking the jar with its weight and number is by means of a pencil on a rough surface etched with diamond ink. Every Monday, Wednesday and Friday, each jar was placed on a coarse balance, and water added through the test-tube until its original weight was restored.

After four weeks the contents of the jars were mixed thoroughly. One hundred grams were placed in a funnel on a perforated porcelain disk, and washed with water until the volume of the filtrate was about Ioo cc. Nitrates were then determined in the filtrate by the Tiemann-Schulze method, and calculated to the original weight of the mixture.

For the ammonia determination, an amount equal to 200 grams of the dry soil was placed in a flask with dilute hydrochloric acid $(\mathrm{I}: 25)$ in quantity sufficient to make $500 \mathrm{cc}$. with the water contained in the sample. The mixture of soil and acid was shaken thoroughly, filtered after standing over night, and 250 cc. of the filtrate distilled with magnesia. The ammonia was caught in standard acid and the solution titrated back with ammonia. Correction was made for ammonia in the reagents. Both nitric and ammoniacal nitrogen were corrected for the quantity present in the original soil.

Both determinations were made in duplicate jars; as a rule the nitrate determinations agreed very well, while the ammonia determinations were less satisfactory.

\section{RESULTS OF NITRIFICATION.}

The nitric nitrogen produced, in percentage of total nitrogen added in the fertilizer, and the relative value of the materials on this basis, are presented in Table I. The results are similar to those in the paper of Withers and Fraps already referred to; namely, that the rank of the fertilizers measured by the relative amounts of nitrates produced from them varies according to the nature of the soil.

These variations are apparently due, in large part, to other 
fertilizing constituents carried by the materials. From unpublished work of the author it appears that acid phosphate, potassium sulphate, or calcium sulphate, one or more, may sometimes have a decided effect upon nitrification on many soils, and a low nitrifying power may sometimes be due to deficiency in plant food for the nitrifying organisms. Ammonification is decidedly less sensitive. Referring to Table I, we

\begin{tabular}{|c|c|c|c|c|c|c|}
\hline \multirow[b]{2}{*}{ Material. } & \multicolumn{3}{|c|}{$\begin{array}{l}\text { ercentage of added nitrogen } \\
\text { oxidized to nitrates. }\end{array}$} & \multicolumn{3}{|c|}{ Rank. } \\
\hline & In soil & $\begin{array}{c}\text { In soil } \\
77 .\end{array}$ & $\begin{array}{c}\text { In soil } \\
\text { I31. }\end{array}$ & $\begin{array}{l}\text { In soil } \\
75 .\end{array}$ & $\begin{array}{c}\text { In soil } \\
77 .\end{array}$ & $\begin{array}{c}\text { In soil } \\
13 \mathrm{~T} .\end{array}$ \\
\hline Cottonseed meal...... & 8.2 & 20.3 & 7.6 & 100 & 100 & 100 \\
\hline Blood $\ldots \ldots \ldots \ldots \ldots \ldots$ & . 6.6 & 23.1 & $5 \cdot 9$ & 80 & I I4 & 79 \\
\hline Bone.................... & I 8.6 & 17.6 & 21.9 & 227 & 87 & 288 \\
\hline Bat guano......... & . $17 \cdot 5$ & 17.8 & 22.0 & 213 & 87 & 289 \\
\hline Cow manure........... & . lost & 9.9 & 8.9 & lost & 49 & I I 7 \\
\hline
\end{tabular}

find that the high rank of bone and bat guano in soils 75 and $\mathrm{r} 3 \mathrm{r}$, and of cow manure in soil $\mathrm{I} 3 \mathrm{I}$, is not due so much to increased nitrification of these materials, as to decreased nitrification of cotton-seed meal and blood. A close comparison is not permissible, since the initial number and activity of the organisms in each series was probably not exactly the same. ${ }^{1}$ The decreased nitrification of the cotton-seed meal and blood in the two soils was probably due to deficiency in phosphoric acid in the soil, which is carried by the bone and bat guano in large quantity; and indeed by cotton-seed meal also, though not in sufficient amount. This explanation of the difference in nitrification in the soils is in accordance with the effect of the different materials in soil $\mathrm{r} 3 \mathrm{I}$, as follows:

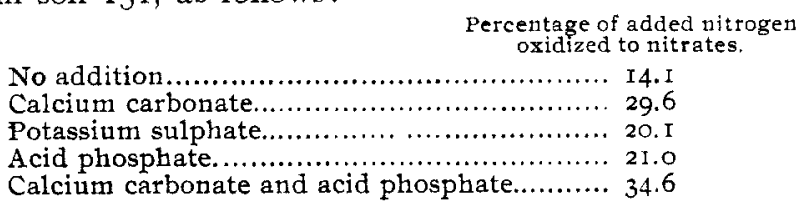

From this it would appear that some soils are sometimes deficient in phosphoric acid and potash for the nitrifying organisms, and fertilization with these ingredients may increase nitrification.

AMMONIFICATION AND NITRIFICATION.

The sum of the ammoniacal and nitric nitrogen from the different materials, expressed in terms of the total nitrogen applied,

1 See Fraps: Am. Ch. J. 29, 225 (I903). 
is given in Table II, and also the relative values of the fertilizers on this basis. Some variations are to be found, as can be expected, but they are moderate and by no means as great as with the nitrates taken alone. They are probably due to differences in the nature of the soil. The relative amounts of nitric plus ammonia nitrogen depend most largely upon the nature of the material, and are in the order of the availability of the fertilizer.

\begin{tabular}{|c|c|c|c|c|c|}
\hline \multirow[b]{2}{*}{ Material. } & \multicolumn{2}{|c|}{$\begin{array}{l}\text { Percentage of nitrogen converted } \\
\text { into nitrates and ammonia. }\end{array}$} & \multicolumn{3}{|c|}{ Rank. } \\
\hline & $\begin{array}{l}\text { In soil } \\
77\end{array}$ & $\begin{array}{l}\text { In soil } \\
\text { 131. }\end{array}$ & $\begin{array}{l}\text { In soil } \\
75 .\end{array}$ & $\begin{array}{l}\text { In soil } \\
77 .\end{array}$ & $\begin{array}{l}\text { In soil } \\
\text { I3I. }\end{array}$ \\
\hline Cottonseed meal.... 5I.5 & 39.4 & 49.3 & 100 & 100 & 100 \\
\hline Blood .................. 56.4 & 43.9 & 42.9 & IIO & I I I & 86 \\
\hline Bone................. 20.7 & 23.9 & $23 \cdot 7$ & 40 & $6 r$ & 47 \\
\hline Bat guano............. 29.I & 24.8 & 33.5 & 57 & 63 & 67 \\
\hline Cow manure................ & 9.6 & 8.3 & ...... & 24 & I 7 \\
\hline
\end{tabular}

An obvious inference from this statement is that the ammonifying group of organisms is apparently not as sensitive to the condition of the plant food in the soil as the nitrifying organisms, perhaps having greater power of securing it. This inference appears justified from work on the effect of various additions to the soil upon nitrification and ammonia production.

The absolute amount of nitrates and ammonia formed would probably depend upon the number and activity of the organisms with which the soil was inoculated at the beginning of the experiment, as well as on the nature of the material and the conditions of the experiment. Forty-three to 56 per cent. of the nitrogen of dried blood was changed into ammonia and nitrates in four weeks under the conditions of these experiments. This is considerably less than 73 per cent., which is probably the average value for the availability of blood compared with sodium nitrate as 100 in vegetation experiments. With a longer period of time for nitrification, more of the nitrogen would be converted into nitrates and ammonia.

\section{RATE OF TRANSFORMATION.}

The nitrogen recovered as ammonia and nitrates in our tests represents the more readily available nitrogen of the material, or that which is most easily attacked by bacteria. The transformation will continue at a decreasing rate, until it will become so slow as to be practically indistinguishable from the change of the soil nitrogen. 
We have determined the rate of production of nitric and ammonia nitrogen in soil 77. A set of ro jars was prepared under the same conditions, and kept in the constant temperature bath. Every week two jars were removed for the determination of nitrates and ammonia. Correction was made for the original content of nitrates and ammonia. The results (average of duplicates) are presented in Table III.

TABI. III.-RATE OF Change FOR THE NITROGEN OF COTTONSEED MEAL.

\begin{tabular}{|c|c|c|c|}
\hline \multirow[b]{2}{*}{ Time in days. } & \multicolumn{3}{|c|}{ Percentage of nitrogen converted during each period in } \\
\hline & nitrates. & ammoria. & total. \\
\hline 7 & -0.4 & +22.2 & +21.8 \\
\hline 15 & +7.0 & $\div 4.1$ & -11.6 \\
\hline 21 & +8.8 & -4.1 & +4.7 \\
\hline 28 & +7.8 & -5.7 & +2.1 \\
\hline 35 & $+3 \cdot 5$ & +2.2 & +5.7 \\
\hline 42 & +0.8 & -0.9 & -0.1 \\
\hline 49 & $+\mathrm{I} .0$ & $-4.8^{1}$ & -3.8 \\
\hline 56 & +1.2 & -3.6 & +4.8 \\
\hline Total.. & ... 29.7 & 16.6 & 46.3 \\
\hline
\end{tabular}

1 This is perhaps an error.

Nitrification begins the second week, and reaches its maximum during the third, and decreases to the sixth week, after which the rate increases slightly; that is to say, the nitrification is periodic, as pointed out in a previous article. The total change (sum of nitric and ammoniacal nitrogen) is greatest during the first week, and decreases to the fourth, after which it is somewhat irregular. The ammonia formation has its maximum during the first week, and is positive during the second, after which it is for the most part negative, owing to change into nitrates. However, the ammonia formation goes on during almost all the periods, since the total change is positive in every period save two, although we must also consider the possibility of direct conversion of organic nitrogen into nitrates, without passing through the intermediate ammonia stage. There is evidence in favor of the view that such a direct change takes place.

At the end of fifty-six days, the nitrogen of the cottonseed meal was distributed as follows:

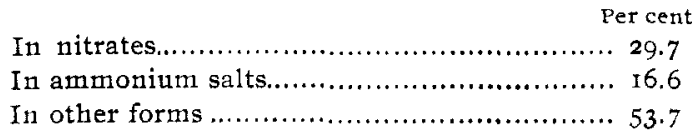




\section{COMPARATIVE VALUE OF AMMONIA AND NITRATES.}

The facts presented in this paper lead us to the opinion that the ammonia nitrogen of the soil is of more importance than is generally held to be the case. The statement that nitric nitrogen is the only form in which nitrogen is assimilated by cultivated plants has been noted several times lately. ${ }^{1}$ There is evidence that plants are able to assimilate ammonia, and some organic bodies such as asparagin, glycocoll and urea in addition to nitrates, leaving out of consideration the assimilation of atmospheric nitrogen by leguminous plants in symbiosis with bacteria. While nitrates are usually more abundant in cultivated soils than ammonia, yet the ammonia is present, and being present may be assimilated. In rice-growing, when the soils are saturated with water during most of the growing season, and in some compact soils, where physical condition is little favorable to nitrification, nitrates cannot play a great rôle in the nutrition of the plants.

The experiments here described have shown that at the end of four and even eight weeks, under conditions favorable for nitrification, a large portion of the nitrogen rendered assimilable to plants by changes in the soil is often present as ammonia (see Table IV). This proportion will of course decrease with time, Table IV.-Ammontacal Nitrogen in ioo Parts Nitric and amMONIACAI, NITROGEN.

\begin{tabular}{|c|c|c|c|}
\hline \multirow{2}{*}{\multicolumn{4}{|c|}{ Soil. }} \\
\hline & & 77. & \\
\hline Cottonseed meal................. & 84 & 49 & 8 \\
\hline Blood ............. & 88 & 47 & 8 \\
\hline Bone ......... & ro & 26 & 8 \\
\hline Bat guano ............................. & 40 & 29 & 34 \\
\hline Cow manure. & lost & 0 & 0 \\
\hline
\end{tabular}

but the nitrification is slow after four weeks. Such being the case, it is obvious that ammonia must play a not insignificant part in plant nutrition when fertilizers or manures are applied. It may be objected that the ratio of soil to fertilizer is smaller than in practice, and with the same quantity of material in a larger quantity of soil, nitrification will take place more rapidly.

${ }^{1}$ C. G. Hopkins : Bulletin 94, Ill. Expt. Station, page I; Chester : Bulletin 40, Del. Expt. Station ; Patterson : Bulletin 9I, Md. Expt. Station, page 28 ; Stubbs : Bulletin 77, La. Expt. Station ; Harris : "Food for Plants," p. 6; F. H. King: "Year Book," U. S. Dept. of Agric. 1903, p. I70. 
This objection must be considered, but we must remember that in the field the fertilizer is not mixed intimately with all the soil to the depth of twelve or six or four inches, but is distributed in the row or broadcast, often in a lumpy condition, and comes in direct contact with only a limited quantity of the soil to which it is applied.

If plants depend entirely upon nitrates for nitrogen, the fertility of a soil should depend largely upon its ability to support the nitrifying organisms, and the availability of organic fertilizers would vary with the nitrifying power of the soil to which they are applied. If both ammoniacal and nitric nitrogen were assimilated with equal readiness by plants, the fertility of the soil would bear little relation to its nitrifying power, since the production of ammonia seems to depend more on the material than on the soil. Nitric and ammoniacal nitrogen are probably of unequal value, varying with the nature of the plant. In most cases the nitric nitrogen is probably more easily absorbed than ammonia; the nitrifying power of a soil must therefore be of some influence upon its fertility, though not so great as if ammonia were totally unavailable.

Unfortunately, we have no quantitative determination of the availability of ammoniacal compared with nitric nitrogen under conditions excluding nitrification of the ammonia. In pot and field tests, in which more or less of the ammonia is nitrified, ammonium salts as a rule are not equal to nitrates. The difference has been ascribed to the beneficial effect of the sodium of the sodium nitrate, ${ }^{2}$ or to the injurious effect of the acid residue of ammonium sulphate, but it may also be due to the incomplete nitrification of ammonia, and the lower capacity of the latter to serve as nourishment for the plants under study. Wagner ${ }^{2}$ assigns the value go to the nitrogen of ammonium salts, compared with sodium nitrate nitrogen as roo. Wheeler ${ }^{3}$ found nitrogen in ammonium sulphate to have the value 92.2 on a limed soil, less than nothing on the unlimed acid soil, with nitric nitrogen equals 100 as the standard.

"P. Wagner: "Die Stickstoffdüngung der landwirtschaft1. Kulturpflan zen, I892."

"Loc. cit. Later he gives a value of 94 as an average for all pot experiments, Ausführung v. Felddüngungsversuchen, r 904.

${ }^{3}$ Rhode Island Bulletin, No. 53 . 
It seems probable that ammonia nitrogen, as such, has a lower value for most cultivated plants than nitric nitrogen. Such being the case, the nitrifying power of a soil must have some influence upon the crop value of the fertilizer nitrogen placed in it.

\section{DETERMINATION OF AVAILABILITY OF NITROGEN.}

Vegetation tests for comparing the values of nitrogen in different forms are influenced by a number of variables, as the nature of the soil, the kind of plant, the season and the effect of the fertilizer on succeeding crops, all of which must enter into consideration. The results of different individual experiments vary considerably. Thus for the nitrogen of blood, compared with that of sodium nitrate as Ioo, we have the figures $76,68,73,95,58,61,85,69$, $68,73,73,83,5 \mathrm{I}{ }^{1}$ as values in separate experiments by several workers. The average of several series of experiments may agree better. Thus Jenkins and Britton's average for three years was 73 , Wagner's average is 69 , von Sigmond's 67 , Pfeiffer, Franke, et al., is 85 .

As regards the effect of the soil, Wheeler found the availability of the nitrogen of dried blood to be 45.5 in an unlimed acid soil, 90.3 in the same soil limed, compared with sodium nitrate nitrogen as Ion, while ammonium sulphate had the availability of less than zero in the acid soil, 92.2 in the limed soil.

Availability will also depend to a certain extent upon whether one or several crops is taken up for the measurement. Quickacting fertilizers will appear comparatively more available with one crop than with several, in which the slower have greater chance to show results.

It will be concluded that the amount of assimilable nitrogen that can be produced from a given substance is a measure of its availability. It is not the fault of the material if the soil conditions are such that the maximum of assimilable bodies is not produced, or, being produced, if the plant is unable to take them up, because they are washed out, fixed, or for other reasons.

To compare organic materials with sodium nitrate directly, it would be necessary to select such a period of time and such

${ }^{1}$ Experiment Station Record, 7, I93; 8, 387; 9, 54I ; 10, 233; I2, 323 ; 13, 323; Ix, 134; 14, 557; I5, 235, 660. Jenkins and Britton : Experiment Station Record, Io, 233. Wagner average: Ibid. II, I34. Von Sigsmond average: Ibid. 15, 660. Pfeffer, Franke, et al., Ibid. I I, I34. 
conditions, that the substance would be converted into as much assimilable compounds as it would be during the growing season of the plant. According as the time selected is longer or shorter and the number and activity of the soil organisns used to inoculate the soil increase or diminish, different results would be obtained. The comparison of organic materials directly with sodium nitrate is thus subject to serious difficulties.

The comparison of different organic materials does not offer such difficulties, and it is believed that the method, as pointed out in this paper, will be of value for this purpose. It can neither supplant vegetation tests, nor take the place of a rapid chemical method for determining availability, but in its own sphere should be of value. The work in this paper has been confined to the amount of nitric and ammonia nitrogen formed; as has been stated, some organic compounds may be assimilated directly by the plants, but the determination of the amounts of such of these as are formed in the decomposition of organic matter in the soil, offers grave analytical difficulties.

SUMMARY.

(I) Nitrogenous fertilizers may be divided into two classes: those which are compounds directly assimilable by plants, and those which must first be converted into assimilable bodies before the nitrogen is of value.

(2) The rank of fertilizers measured by the relative amount of nitrates produced from them depends upon the nature of the soil.

(3) These variations depend sometimes upon the need of the soils for the other fertilizing ingredients carried by the material.

(4) The relative amounts of nitric and ammoniacal nitrogen produced from different material under similar conditions depend most largely upon the nature of the materials, and is in the order of their availability. The soil is, however, of some effect.

(5) The ammonifying group of organisms is not so sensitive to the condition of plant food in the soil as the nitrifying organisms.

(6) In an experiment to test the rate of formation of nitrates and ammonia, ammonia was formed most rapidly during the first week, and is positive during the second, after which it is for 
the most part negative, owing to conversion into nitrates. Nitrification begins the second week, reaches its maximum during the third week, then decreases; that is, it is periodic. The total change is greatest during the first week, and decreases to the fourth, after which it is somewhat irregular.

(7) Since a large part of the nitrogen rendered available is in the form of ammonia, it is probable that ammonia plays a greater part in plant nutrition than is commonly assumed to be the case.

(8) Ammonia is probably of less value than nitrates for most cultivated plants, and the nitrification power of soils is of importance.

(9) Determination of the relative amounts of nitric and ammonia nitrogen produced from them should be of value in comparing different organic materials.

[CONTRIBUTION FROM THE COMMITTEE ON UNIFORMITY IN THCHNICAI ANALYSIS. II.]

\section{COOPERATIVE ANALYSIS OF AN ARGILLACEOUS LIME- STONE.}

Received December 30, 1905.

INTRODUCTION.

THE present contribution deals with the results obtained in an effort of the committee to secure information of the nature indicated in the second paragraph of the list of its aims as published in this Journal 26, I652. In other words, to endeavor to ascertain if a part of the blame for the notorious inability of different analysts to report closely agreeing results when analyzing the same materials is to be placed upon the instructors in analytical chemistry in our higher institutions of learning. The subject is, of course, a difficult one to handle, but it was hoped that by a frank invitation to coöperate a sufficient number of public-spirited instructors, earnestly desirous of improving a plainly serious situation, might be secured to afford some positive indication one way or the other.

To this end a circular letter was addressed on Jan. I, I905, to the heads of the chemical departments in nearly roo universities, colleges, polytechnics and mining schools throughout this country and Canada. It was proposed to send to all who might be willing to have an analysis or analyses made by their instructors or advanced 